\title{
A possible link between improper use of carbapenems and prevalence of carbapenem- resistant Klebsiella Pneumoniae in a hospital
}

Zhonglin Chai ( $\nabla$ zhonglin.chai@monash.edu )

Monash University Central Clinical School https://orcid.org/0000-0001-8182-8579

\section{Yuxin Yang}

Zunyi maternity and Child Health care Hospital

Jia Liu

Zunyi Maternity and Child Health Care Hospitaal

Muhammad Murad

University of Melbourne

\section{Zongsu Min}

Zunyi Meternity and Child Health Care Hospital

Jing Lu

People's Hospital, Guiyang

\section{Research}

Keywords: Carbapenemase Genes, CRKp, ERIC-PCR

Posted Date: June 8th, 2020

DOl: https://doi.org/10.21203/rs.3.rs-33310/v1

License: (9) (i) This work is licensed under a Creative Commons Attribution 4.0 International License. Read Full License 


\section{Abstract}

Background: The emergence of carbapenem-resistant Enterobacteriaceae made the treatment difficult, which has become a major issue of public health. A sharp increase of carbapenem-resistance rate in Klebsiella pneumoniae was observed in a maternity and child health care hospital in Zunyi, China, in 2014. To investigate the cause and epidemiology of the carbapenem-resistant Klebsiella pneumoniae (CRKp) in the affected hospital.

Methods: In 2015-2016, CRKp isolated from all the clinical samples were analyzed to identify the carbapenem-resistance genes. They were then fingerprinted in order to determine their genetic relationship. Clinical data such as usage of imipenem in 2012-2016 and the nosocomial infection surveillance data were analyzed

Results: Thirty five isolates of CRKp out of 4328 various pathogens were obtained and $b / a_{\mathrm{NDM}-1}$ was identified to be the most common resistant gene present in the CRKp isolates. The fingerprint analysis identified 15 major clusters of CRKp isolates. The bacteria with close proximity relationship tended to be from the same wards. However, a few CRKp isolates from different wards were found to be genetically highly related. The clinical data showed a significantly higher usage of carbapenems in 2012-2013, before the CRKp rate sharply increased in 2014. The nosocomial infection surveillance showed unexpected high rate of failures to meet the requirement of the hospital environment hygiene and hand hygiene in the neonatal ward.

Conclusion:The increasing isolation rate of CRKp was associated with poorly regulated usage of carbapenems, impropriate medical practices and the poor hospital environmental hygiene and hand hygiene.

\section{Background}

K. pneumoniae is a gram-negative encapsulated bacillus belonging to the Enterobacteriaceae family. It is commonly known as an opportunistic bacterial pathogen in humans being responsible for a number of diseases such as respiratory tract infections, urinary tract infections (UTIs) and bloodstream infections[1]. K. pneumoniae is also the most common cause of bloodstream infection resulting from the hospitalacquired infections (HAls) [2]. According to the US statistics, the total annual cost for the HAls infections was 8.3-11.5 billion dollars in 2013 alone [3]. In China, gram-negative bacteria are the third most common cause of hospital-acquired pneumonia [4], hence being a major potential risk of increases in the associated morbidity for the hospitalized patients and health care cost. Furthermore, if the pathogens become resistant to commonly used antibiotics, they can increase mortality, especially in the case of carbapenem-resistant Enterobacteriaceae (CRE). Since an audit carried out in our hospital revealed that there was a sharp increase of carbapenem resistance rates in K. pneumoniae in 2014, this study was initiated to analyze the clinical data of inpatients from 2012-2016, in order to understand the overall usage of carbapenems during the period in the hospital. The CRKp isolates obtained from the clinical 
sample of 2015-2016 were analyzed to determine the genes responsible for carbapenem resistance as well as fingerprinting analysis to establish the genetic relationship among these isolates.

\section{Methods}

\section{Materials}

Columbia Blood Agar and Mueller-Hinton agar were purchased from Zhengzhou Beiruite Biotechnology. Inc. (Zhengzhou, China). Meropenem E-test Strips (Oxoid. Inc.) and Vitek 2 Compact (BioMérieux. Inc.) were purchased from respective commercial companies. Primers were synthesized by GenScript (Nanjing. Inc.) with their sequences shown in Table 1. Real-Time PCR agents were from TransGen Biotech. Inc). Ezup Column Bacteria Genomic DNA Purification Kit (Sangon Biotech Shanghai. Inc), ABI 7500 Real Time PCR System (Thermo Fisher Scientific. Inc.), PowerPac Basic, Mini-Sub cell and Gel Doc ${ }^{\text {TM }}$ XR+ system (Bio-Rad Laboratories. Inc) were purchased from specified companies.

\section{Clinical specimens}

All the non-duplicate CRKp isolates were isolated from the clinical samples collected from various wards by growing on Columbia Blood Agar during 2015 2016. The resistance to antibiotic imipenem was detected by Vitek 2 Compact, then confirmed by imipenem E-test. These CRKp, with their imipenem minimum inhibitory concentrations (MICs) being $\geq 4 \mu \mathrm{g} / \mathrm{ml}$, were stored in $10 \%$ skim milk at $-70^{\circ} \mathrm{C}$ before analysis.

\section{Detection of carbapenemases genes and sequencing}

The CRKp isolates stored at $-70^{\circ} \mathrm{C}$, were inoculated in LB media and incubated at $37^{\circ} \mathrm{C}$ overnight and their genomic DNA was purified using Ezup Column Bacteria Genomic DNA Purification Kit. Carbapenemase genes ( $\left.b / a_{\mathrm{SME}}, b / a_{\mathrm{IMP}}, b / a_{\mathrm{OXA}-48}, b / a_{\mathrm{KPC}}, b / a_{\mathrm{NDM}}, b / a_{\mathrm{VIM}}\right)$ were detected by using Real-Time PCR with specific primers as shown in Table 1. The PCR conditions were pre-denaturing at $94^{\circ} \mathrm{C}$ for $30 \mathrm{~s}$ followed by 40 cycles of $94^{\circ} \mathrm{C} 5 \mathrm{~s}$ for denaturing, $58-62^{\circ} \mathrm{C} 34 \mathrm{~s}$ for primer annealing and $72^{\circ} \mathrm{C} 30$ s for product extension. At the end of amplification, the PCR products were melted at $95^{\circ} \mathrm{C} 15 \mathrm{~s}, 60^{\circ} \mathrm{C} 1 \mathrm{~min}, 95^{\circ} \mathrm{C} 30 \mathrm{~s}$, $60^{\circ} \mathrm{C} 15 \mathrm{~s}$ to determine the melt curve). Ten PCR products were randomly sequenced to confirm the identity of the PCR products.

Table 1 Primer Sequences for Carbapenemases Genes 


\section{Carbapenemases Primer sequence}

genes

\begin{tabular}{ll}
\hline bla & F: 5'-TTAACACTGCAATCCCAGGAGA-3' \\
& R: 5'-CTACAACCCAATCAGCAGGAAC-3' \\
\hline$b / a_{\text {IMP }}$ & F: 5'-GCTTGATGAAGGCGTTTATGTT-3' \\
& R: 5'-CTGTCGCTATGAAAATGAGAGGA-3' \\
\hline$b / a_{0 X A-48}$ & F: 5'-AGCAAAGGAATGGCAAGAAAAC-3' \\
& R: 5'-TAAAGGTAGATGCGGGTAAAAAT-3' \\
\hline bla $a_{\mathrm{KPC}}$ & F: 5'-TTGATTGGCTAAAGGGAAACACGAC-3' \\
\hline bla & GCCAGACGACGGATAGTCATTT-3' \\
& F: 5'-GCAGTCGCTTCCAACGGTTT-3' \\
bla & R: 5'-CAAGCTGGTTCGACAACGCA-3' \\
& F: 5'-GTCGCATATCGCAACGCAGT-3' \\
& R: 5'-CGACGCGGTCGTCATGAAAG-3'
\end{tabular}

\section{ERIC-PCR}

Enterobacterial Repetitive Intergenic Consensus PCR (ERIC-PCR) was performed on the purified genomic DNA using ERIC primers (ERIC-1R 5'-ATGTAAGCTCCTGGGGATTCAC-3', ERIC-2 5'AAGTAAGTGACTGGGGTGAGCG-3') [5, 6]. The DNA was Amplified as following: $94^{\circ} \mathrm{C} 1 \mathrm{~min}, 52^{\circ} \mathrm{C} 1 \mathrm{~min}$, $68^{\circ} \mathrm{C} 8 \mathrm{~min}$ for $38 \mathrm{cycles} ; 65^{\circ} \mathrm{C} 16 \mathrm{~min}$ for 1 cycle. Then the PCR product was electrophoresed on $2 \%$ agarose gel containing $0.25 \mathrm{ug} / \mathrm{ml}$ of ethidium bromide. These gels were photographed in $\mathrm{Gel} \mathrm{Doc}^{\mathrm{TM}} \mathrm{XR}+$ system.

\section{Clinical data collection}

The clinical data were retrieved from the database recorded in the department of pathology and other relevant departments of the hospital for analysis. These included the inpatients in 2012 to 2016, and their detection of 4 imipenem-resistant Enterobacteriaceae pathogens, Escherichia coli(E. coli), Klebsiella pneumoniae(K. pneumoniae), Enterobacter cloacae(E.cloacae) and Klebsiella oxytoca(K. oxytoca). Data were used for analysis to determine whether these patients having received imipenem treatment, and other $\beta$-lactam in addition to imipenem, had their infection confirmed by isolation of pathogens as well as whether those pathogens were Extended-Spectrum Beta-Lactamases(ESBLs)-Producing, which is one of the criteria to justify the use of imipenem.

\section{Nosocomial infection surveillance data}


Nosocomial infection surveillance data in 2012 to 2016 were retrieved from the hospital database, which include the bacteria count of air and doctors' and nurses' hands from the wards in which CRKp cases were identified.

\section{Data Analysis}

The fingerprint bands of CRKp produced by ERIC-PCR were analyzed, the cluster data table and the relative distance and the Dendrogram were generated by using SPSS 19.0. The differences of genotypes are displayed according to relative distance among strains.

\section{Results}

\section{1. bla $a_{\mathrm{NDM}-1}$ is the most common carbapenemase gene in the CRKp isolates}

Totally 35 CRKp isolates out of 4328 various pathogens were analyzed $₫$ which were collected in 20152016 from neonatal ward, pediatric wards 2 and 3 as well as Pediatric Intensive Care Unit (PICU), representing an overall $\sim 0.81 \%$ detection rate. Most of the CRKp isolates $(25 / 35, \sim 71 \%)$ were from the neonatal ward with 6 from the PICU $(\sim 17 \%)$ and $4(\sim 11 \%)$ from the two pediatric wards. Almost all the CRKp strains were isolated from the sputum samples, except for two with one from tracheal intubation (ID\# 9 from neonatal ward) and the other from blood (ID\#35 from PICU), as enlisted in Table 2.

Twenty six out of $35 \mathrm{CRKp}$ isolates were detected to contain $b / a_{\mathrm{NDM}-1}$ gene $(74 \%) ; 3$ had $b / a_{\mathrm{NDM}-1}$ and $b / a_{\mathrm{KPC}}$ genes (9\%); 2 had both $b / a_{\mathrm{NDM}-1}$ and $b / a_{\mathrm{VIM}}$ genes $(6 \%) ; 1$ had both $b / a_{\mathrm{NDM}-1}$ and $b / a_{\mathrm{IMP}}$ genes (2.5\%); 1 had bla 2). Moreover, 10 randomly chosen $b / a_{\mathrm{NDM}-1}$ PCR products were sequenced and the results confirmed that they were all correct specific products of the $b / a_{\text {NDM-1 }}$ gene.

Table 2 Detection of carbapenemase genes in CRKp isolates from specified wards* 


\section{Source of bacterial Carbapenemase gene}

\section{Inpatient}

isolates

ID $\quad$ ward

73 Pediatric sputum

Ward-3

11 Pediatric sputum

Ward -2

$b / a_{\mathrm{KPC}} \quad b / a_{\mathrm{NDM}} \quad b / a_{\mathrm{OXA}} \quad b / a_{\mathrm{IMP}} \quad b / a_{\mathrm{VIM}} \quad b / a_{\mathrm{SME}}$

Pediatric sputum

Ward -2

71 Pediatric sputum

Ward -2

35 PICU blood

36 PICU sputum

65 PICU sputum

75 PICU sputum

76 PICU sputum

$77 \quad \mathrm{PICU}$

sputum

9 Neonatal tracheal intubation

Ward

10 Neonatal sputum

Ward

12 Neonatal sputum

Ward

13 Neonatal sputum

Ward

19 Neonatal sputum

Ward

20 Neonatal sputum

Ward

21 Neonatal sputum

Ward

22 Neonatal sputum

Ward

23 Neonatal sputum

Ward

24 Neonatal sputum 
Ward

\begin{tabular}{|c|c|c|c|c|c|c|c|c|}
\hline 34 & $\begin{array}{l}\text { Neonatal } \\
\text { Ward }\end{array}$ & sputum & - & + & - & - & - & - \\
\hline 38 & $\begin{array}{l}\text { Neonatal } \\
\text { Ward }\end{array}$ & sputum & - & + & - & - & - & - \\
\hline 45 & $\begin{array}{l}\text { Neonatal } \\
\text { Ward }\end{array}$ & sputum & - & - & - & - & - & - \\
\hline 46 & $\begin{array}{l}\text { Neonatal } \\
\text { Ward }\end{array}$ & sputum & - & - & - & - & - & + \\
\hline 49 & $\begin{array}{l}\text { Neonatal } \\
\text { Ward }\end{array}$ & sputum & - & + & - & - & - & - \\
\hline 50 & $\begin{array}{l}\text { Neonatal } \\
\text { Ward }\end{array}$ & sputum & + & + & - & - & - & - \\
\hline 51 & $\begin{array}{l}\text { Neonatal } \\
\text { Ward }\end{array}$ & sputum & - & + & - & - & - & - \\
\hline 53 & $\begin{array}{l}\text { Neonatal } \\
\text { Ward }\end{array}$ & sputum & - & + & - & - & - & - \\
\hline 54 & $\begin{array}{l}\text { Neonatal } \\
\text { Ward }\end{array}$ & sputum & - & + & - & - & - & - \\
\hline 59 & $\begin{array}{l}\text { Neonatal } \\
\text { Ward }\end{array}$ & sputum & - & + & - & - & - & - \\
\hline 60 & $\begin{array}{l}\text { Neonatal } \\
\text { Ward }\end{array}$ & sputum & - & + & - & - & - & - \\
\hline 61 & $\begin{array}{l}\text { Neonatal } \\
\text { Ward }\end{array}$ & sputum & - & + & - & - & - & - \\
\hline 62 & $\begin{array}{l}\text { Neonatal } \\
\text { Ward }\end{array}$ & sputum & - & + & - & - & - & - \\
\hline 63 & $\begin{array}{l}\text { Neonatal } \\
\text { Ward }\end{array}$ & sputum & - & + & - & - & - & - \\
\hline 72 & $\begin{array}{l}\text { Neonatal } \\
\text { Ward }\end{array}$ & sputum & - & + & - & - & + & - \\
\hline
\end{tabular}

*The detection results of specified carbapenamase genes in samples from corresponding wards are expressed as either positive $(+)$ or negative $(-)$.

\section{CRKp with closely related genotypes can be detected in patients from different wards}

ERIC-PCR analysis divided the 35 CRKp isolates into 15 major clusters (A-O) (Figure 1). In each cluster, the isolates had high genotypic similarity with cut-off of $<5$ by ERIC-PCR. Ten clusters were isolated from the 
Neonatal Ward (A, B, C, D, E, F, G, H, J, L), 5 from PICU(C, G, J, K,O), 2 from Pediatric Ward-2 (I, M), 1 from Pediatric Ward-3 (N). More than half of CRKp isolates belonged to Clusters A (8/35) and C (10/35). In addition, ERIC-PCR results revealed 12 strains in 5 clusters or sub-clusters with the highest genetic similarity, being sub-clusters a $(10,9), b(61,60), c(22,13,12$ and 24$)$ from Neonatal ward and cluster M $(71,70)$ from PICU, as well as cluster $\mathrm{J}(54,75)$ with one $(54)$ from Neonatal ward and the other $(75)$ from PICU. It was noted that most of the genetically related isolated were from the same wards, but there were a few clusters of isolates found in different wards, such as the clusters C, G and J being found in PICU and neonatal wards.

\section{Imipenem overuse prior to the increase of CRKp prevalence}

The imipenem treatment of the patients and the imipenem resistance of the pathogens isolated from these patients were retrospectively analyzed. As shown in Figure 2, the imipenem-resistant $K$. pneumoniae were barely detected in 2012 and 2013, but $>16 \%$ isolated $K$. pneumoniae were found to be imipenem resistant in 2014, and the imipenem resistance rate in $K$. pneumoniae isolates remained high, at $\sim 10 \%$, in the following 2 years. The imipenem resistant $E$. coli were also found to be increased in 2014 and $2015(<2 \%)$ and further increased to $>6 \%$ in 2016, while no obvious imipenem resistance was found in the E. cloacae and K. oxytoca isolates in 2012-2016.

Analysis of the clinical data recorded in 2012-2016 (Table 3) shows that in 2012 and 2013, there were 116 and 137 inpatients, respectively, who had been treated with imipenem. Among them, 89 and 77 were either bacterial pathogen negative or not tested for bacterial pathogens at all, representing $77 \%$ and $56 \%$, respectively, of the patients having received the imipenem treatment. Among the pathogen positive and imipenem-treated inpatients, approximately 37\% and 31\% of them in 2012 and 2013, respectively, had their pathogens determined to be ESBLs producing, which should be considered to be qualified for the use of imipenem. In the following years, the overall number of imipenem-treated inpatients decreased to 92, 55 and 50 in years 2014, 2015 and 2016, respectively. Among them, although the percentage of the pathogen-positive inpatients increased to $64 \%, 46 \%$ and $54 \%$, respectively, the percentage of those with their pathogens determined to be ESBLs producing remained similar, being $42 \%, 32 \%$ and $33 \%$, respectively (Table 3 ).

\section{Table 3 Imipenem resistant rate and imipenem usage $(n / \%)$}


Year Discharged patients(n) Imipenem Imipenem treated patients ${ }^{b}$

\begin{tabular}{|c|c|c|c|c|}
\hline & & treated patients ${ }^{a}$ & Pathogen Negative/ND & Pathogen Positive \\
\hline \multirow[t]{2}{*}{2012} & 11634 & $116(1.00 \%)$ & 89 (77\%) & (23\%) \\
\hline & & & ES & +: $10(37 \%)^{\mathrm{C}}$ \\
\hline \multirow[t]{2}{*}{2013} & 14311 & $137(0.96 \%)$ & 77 (56\%) & (44\%) \\
\hline & & & ESE & $19(31 \%)$ \\
\hline \multirow[t]{2}{*}{2014} & 15287 & $92(0.60 \%)$ & 33 (36\%) & 4\%) \\
\hline & & & ESBL & $25(42 \%)$ \\
\hline \multirow[t]{2}{*}{2015} & 17396 & 55 (0.32\%) & 30 (54\%) & 6\%) \\
\hline & & & ESBL & $(32 \%)$ \\
\hline \multirow[t]{2}{*}{2016} & 23060 & $50(0.22 \%)$ & $23(46 \%)$ & $4 \%)$ \\
\hline & & & ESBL & $(33 \%)$ \\
\hline
\end{tabular}

${ }^{a}$ Count and percentage of inpatients with imipenem treatment among discharged patients.

${ }^{b}$ Count and percentage (\%) of imipenem treated patients with pathogens detected negative or test not done (ND) per year as well as pathogens detected positive. The species of pathogen are shown in the Additional file 1.

${ }^{c}$ Count and percentage (\%) of Enterobacteriaceae pathogens from imipenem-treated patients which produce Extended-Spectrum Beta-Lactamases $\left(\mathrm{ESBLs}^{+}\right)$, a criterium for imipenem treatment.

\section{Neonatal ward were beyond the allowable range of nosocomial infection}

As per the standard for hand hygiene for healthcare workers in healthcare settings WS/T 313-2009 and hygienic standard for disinfection in hospitals GB15982-1995, the allowable range of bacterial count for air and hands are $\leq 200 \mathrm{cfu} / \mathrm{m}^{3}$ and $\leq 5 \mathrm{cfu} / \mathrm{cm}^{2}$, respectively. Table 4 showed that the monthly bacteria count in air of the neonatal ward were beyond the allowable range 3 times in 2012 and increased to 9, 10, 7 and 7 times in years 2013-2016, respectively, . There were 2 times each year of failure to meet the standard of bacterial count on hands in the neonatal ward in 2014 and 2016. The bacterial count in the air of PICU ward also faild to meet the standard 3 times each year in 2013, 2014 and 2016, respectively and once in 2015. The pediatric wards were found to be overall compliant with the hygiene standards in air and on hand with occasional failures for hand hygiene. 
Table 4 Failure to meet the hygiene standards: monthly results of nosocomial infection surveillance*

\begin{tabular}{|c|c|c|c|c|c|}
\hline Wards & 2012 & 2013 & 2014 & 2015 & 2016 \\
\hline Neonatal Ward (Air) & 3 & 9 & 10 & 7 & 7 \\
\hline Neonatal Ward (Hands) & 0 & 0 & 2 & 0 & 2 \\
\hline Ped-1 (Air) & 0 & 0 & 0 & 0 & 0 \\
\hline Ped-1 (Hands) & 0 & 1 & 1 & 0 & 0 \\
\hline Ped-2 (Air) & 0 & 0 & 0 & 0 & 0 \\
\hline Ped-2 (Hands) & 0 & 0 & 1 & 1 & 0 \\
\hline PICU (Air) & 0 & 3 & 3 & 1 & 3 \\
\hline PICU (Hands) & 0 & 0 & 2 & 0 & 2 \\
\hline Ped-3 (Air) ${ }^{* *}$ & - & - & - & 0 & 0 \\
\hline Ped-3 (Hands) ** & - & - & - & 2 & 0 \\
\hline
\end{tabular}

*: Surveillance was performed monthly each year.

**: Data for Ped-3 are unavailable (-) in 2012-2014, which was established in 2015.

\section{Discussion}

The growth of the imipenem resistant rate in $K$. pneumoniae is the fastest among the all species of the Enterobacteriaceae in the hospital in recent years, followed by E. coli (Figure 2). The carbapenem resistance can be caused by the acquisition of plasmids with various carbapenamase genes. Six carbapenemase candidate genes were analyzed in the CRKp isolates in this study. The most frequently identified gene is $b / a_{\mathrm{NDM}-1}$, which is different from the previous findings in China that the common epidemic genotype is found to be $b / a_{\mathrm{KPC}}[7,8]$.

In 2 CRKp isolates (ID\# 35 and ID\# 45) (Table 2), none of these 6 carbapenemase genes were detected, probably because their carbapenem resistance was conferred by other than these 6 resistance genes, or by other mechanisms of resistance, such as porin loss and/or efflux pump activation [9].

Carbapenemases belong to $\beta$-lactamases with the capacity to hydrolyze or inactivate carbapenems. As per the Ambler's molecular classification, the carbapenemases are divided into class $A, B$, and $D[10]$. Serratia marcescens enzyme (SME) and K.pneumoniae carbapenemase (KPC) belong to Class A carbapenemases, their hydrolytic mechanism confers resistance to many $\beta$-lactam antibiotics including carbapenems. Verona imipenemase (VIM), Imipenemase (IMP) and New Delhi metallo- $\beta$-lactamase (NDM) belong to Class $\mathrm{B}$ carbapenemases, which are metallo- $\beta$-lactamases that use a $\mathrm{Zn}^{2+}$ cation for hydrolysis of the $\beta$-lactam ring, and resistant to clavulanic acid, tazobactam, and sulbtactam. Class $D$ 
carbapenemases have been described among four subfamilies of Oxacilinase(OXA)-type $\beta$-lactamases, the intrinsically weaker carbapenemase activity is augmented by coupling $\beta$-lactamase production with an additional resistance mechanism, such as decreased membrane permeability or increased active efflux[11, 12].

Doctors can choose the appropriate treatment according to the prevalence of the specific carbapenemase gene [13]. The behavior of the bacterial pathogens can change as a result of genetic mutations by insertion/deletion of DNA fragment, homologous recombination, spontaneous induction of the SOS response and replication-transcription conflict to adapt to the environment and to resist attack of antibiotics $[14,15]$, consequently leading to generation of antibiotic resistance including resistance to carbapenem. This is a slow process and it is estimated that the spontaneous mutations occur at a rate of $10^{-10}$ to $10^{-9}$ per nucleotide per generation for most of bacteria under certain growth conditions [14]. In this hospital, the resistance rates of CRKp jumped swiftly from 0.0\% in 2013 to $16.9 \%$ in 2014 (Figure 2), which was an usual event and warranted an urgent study to identify the mechanism of this growth in order to develop an effective strategy to prevent further spreading, ultimately reducing the presence of CRKp in the affected hospital.

ESBLs are enzymes produced by some bacterial pathogens that are able to hydrolyze $3^{\text {rd }}$ generation antibiotics such as cephalosporins and aztreonam, leading to nasty resistance to commonly used antibiotics. Carbapenems are beta-lactam antibiotics that have a broad spectrum of activities against many gram-positive and gram-negative, aerobic and anaerobic organisms. Imipenem is the first antibiotic of carbapenems approved as a potent broad-spectrum antibiotic for treatment in 1985. Subsequently, the other carbapenems such as Meropenem, Ertapenem were developed [16]. They are highly stable to resist the hydrolysis by the ESBLs and AmpC beta-lactamases, which are considered to be the "gold standard" treatment for serious ESBL producing pathogen infections[17] and infection of complex bacteria with multi-drug resistance (MDR). Unfortunately, they were tended to be prescribed for conditions suspected to be infection but without pathogens identified or for cases which were not confirmed whether an infection was involved. According to the analysis of the clinical data in this study (Table 3), approximately $1 \%$ of all the discharged patients were treated with imipenem in 2012 and 2013, among whom, most of them had no pathogen detected or no test performed to detect pathogens. Even for the pathogens isolated from a small percentage of patients who received imipenem treatment, only approximately one third of the pathogens identified were confirmed to be ESBLs-producing and most of them were non-ESBLsproducing bacteria or non-enterobacteriaceae bacteria, such as Haemophilus influenzae, Streptococcus pneumoniae, etc(Additional file 1), which should have been treated by antibiotics other than carbapenem.

During this study, irregular combination of medications were also found, including cases who received imipenem combined with other $\beta$-lactams. It appeared that prescription of carbapenem antibiotics was not well restricted and there was lack of robust justification for using carbapenem via collective discussion with experts during those years. Fortunately, the relevant guidelines are now in place. However, the overuse of antibiotics not only occurred at this hospital, but also in other hospitals in China and other countries as having been previously reported $[18,19,20]$. The Average Annual Growth Rate (AAGR) of 
Defined Daily Doses (DDDs) of carbapenem antibiotics of 151 grade A tertiary general hospitals in China from 2011 to 2014 was $17.67 \%$ [18]. At the same time, the rates of imipenem resistance in $K$.

pneumoniae trended to increase from $8 \%$ to $10.5 \%$ in China [19]. In Thailand, the quarterly CRE incidence increased significantly from 3.37 per 100,000 patient-days in the last quarter of 2011 to 32.49 per 100,000 patient-days in the last quarter of 2016 . The quarterly hospital-wide carbapenem consumption increased 1.58 DDDs per 1,000 patient-days in the corresponding time [20]. Obviously, heavy use of this antibiotic is considered to favor selecting resistance mutation and lead to the emergence of CRKp. Schroeder JW has detailed the mechanism of antibiotic resistance previously [14]. A meta-Analysis has revealed that antibiotic usage can lead to resistance mutation, even in animal husbandry where there is a positive association between bacterial resistance and antibiotic consumption in farm animals $[21,22,23$, 24].

Furthermore, our data analysis has shown that, most of the CRKp were isolated from neonatal ward. However, the largest number of prescriptions for imipenem was found to be from the pediatrics words in the early days, and the neonatal ward had the second largest number of prescriptions (data not shown). The clinical data also showed that, firstly, most of the inpatients in the neonatal wards had no corresponding clinical symptoms, albeit they had the highest rate of CRKp pathogen isolation. This suggests that the CRKp in the neonatal patients are likely colonizing in the body, but not responsible for the infection. Secondly, most of the bacteria were isolated from the second time sputum detection from the same inpatient, with the first sputum examination being negative for pathogens. This is highly likely that they acquired the bacteria in the hospital, and these bacteria probably were spreading in the same ward, even between the different wards. The speculation has been supported by the cluster analysis of the pathogen genetic fingerprinting results. Cluster analysis showed that most of the highly similar genotypes bacteria were isolated from the same wards, especially sub-clusters $\mathrm{a}, \mathrm{b}, \mathrm{c}$, and clusters $\mathrm{J}$ and $M$ which were most closely related, suggesting that they were likely spreading between the different inpatients at the same ward. Moreover, the highly related pathogens were also isolated from different wards, such as clusters C, G and J, they were isolated from Neonatal ward and PICU wards. The highly close genetic relationship among these pathogens suggest that they were spreading between the different wards as a result of reproduction of the same bacterial strain. This speculation is supported by the observation that most of these pathogens carry the same resistant gene $b / a_{\mathrm{NDM}-1}$.

It is known that bacteria can acquire external genetic material through three main approaches, transformation (incorporation of naked DNA), transduction (phage mediated) and conjugation (bacterial "sex"). Conjugation is, in particular, a very efficient approach of inter-bacterial gene transfer that involves cell-to-cell contact [25], found to be a key mechanism for the transfer of antibiotic resistant genes between different bacteria. Hospital is prone to contamination of various pathogens, where strict guidelines or rules must be observed for preventing nosocomial infections. A meta-analysis examining 13 risk factors for CRE acquisition has shown that the use of medical devices and carbapenem use in hospitals have the highest association with the CRE acquisition. There are a number of other contributing factors to be noted, such as other antibiotic exposure, underlying disease or condition, invasive

Page 12/19 
procedures, Medical devices, ICU admission, patient demographic characteristics, exposure to hospital care, mechanical ventilation [26]. Indeed, our analysis of the nosocomial infection surveillance data from 2012 to 2016 in this study showed that the bacteria count in air of neonatal ward often exceeded the allowable range every year, for example, it exceeded the limit in 10 of 12 surveys in 2014, indicating that bacterial count in air of the Neonatal Ward was mostly out of control, at least, during the continuous period of time in 2014 and potentially for a long time before and after the year. The pathogens, such as CRKp, could be inhaled into a inpatients' respiratory tract, or it could settle onto the surfaces of body or objects and then acquired by patients during the hospitalization. We have also examined the bacterial count on the hands of doctors or nurses. The data (Table 4) showed that there were several times out of 12 monthly surveys that the hand bacterial count excessed in 2012 and 2016. This data could be underestimated considering that the subjects to be surveyed were notified in advance and prepared for the test, who would have paid more than usual attention to the hand hygiene until detection. Observations and personal conversations indicated that the medical staff tended to not do hand disinfection nor changed gloves between examinations of patients. It is highly likely that the hands contaminated with pathogens would transmit them to everywhere they touched, including the patients, other medical staff, medical devices, even objects around the hospital. The transmission can likely further increase the chance for the antibiotic resistant genes to be transferred among the bacteria existing in the hospital environment. The limitation of this study is that other environmental substances in and around the hospital were not thoroughly examined for the existence of bacteria with antibiotic resistance genes, such as soil, water and waste, which could be important contributing factors [27].

\section{Conclusions}

In conclusion, this study illustrates the molecular characterization and prevalence of CRKp in the maternity and child health care hospital in Zunyi, China. Base on the analysis, the swift increase in the CRKp was associated with poorly regulated usage of carbapenems, impropriate medical practices and the poor hospital environmental hygiene and hand hygiene, as well as the $b / a_{\mathrm{NDM}-1}$ gene is the major contributor for the prevalence of the antibiotic resistance in the pathogen bacteria found in the hospital. The conclusive information should be useful in assisting optimizing the guidelines for controlling the bacterial infection in hospitals as well as helpful for the doctors to make decision in treating patients with infections.

\section{Abbreviations}

CRKp: Carbapenem-resistant Klebsiella pneumoniae

UTIs: Urinary tract infections

HAls: Hospital-acquired infections

CRE: Carbapenem-resistant Enterobacteriaceae

Page 13/19 
K. pneumoniae: Klebsiella pneumoniae

MICs: Minimum inhibitory concentrations

ERIC-PCR: Enterobacterial Repetitive Intergenic Consensus PCR

ESBLs: Extended-Spectrum Beta-Lactamases

PICU: Pediatric Intensive Care Unit

E. coli: Escherichia coli

E. cloacae. Enterobacter cloacae

K. oxytoca: Klebsiella oxytoca

SME: Serratia marcescens enzyme

KPC: K.pneumoniae carbapenemase

VIM: Verona imipenemase

IMP: Imipenemase

NDM: New Delhi metallo- $\beta$-lactamase

OXA: Oxacilinase

MDR: Multi-drug resistance

AAGR: Average Annual Growth Rate

DDDs: Defined Daily Doses

\section{Declarations}

Ethics approval and consent to participate

Not applicable

Consent for publication

Not applicable

Availability of data and materials 
All data generated or analysed during this study are included in this published article [and its supplementary information files]

Competing interests

The authors declare that they have no competing interests

Funding

This work was supported by Zunyi Science and Technology bureau, China. [grant numbers: 48, 2014]

Authors' contributions

YY designed and performed experiments, analyzed data and wrote the manuscript.

$\mathrm{JL}$ analyzed the use of imipenem in 2012-2016.

MM wrote and edited the manuscript.

ZM performed antibiotic susceptibility testing.

J Lu drawn the Dendrogram by SPSS 19.0.

ZC analyzed, interpreted the results, wrote and edited the manuscript.

All authors read and approved the final manuscript.

Acknowledgements

Not applicable

\section{References}

[1] Podschun R, Ullmann U. Klebsiella spp. as nosocomial pathogens: epidemiology, taxonomy, typing methods, and pathogenicity factors. Clin Microbiol Rev. 1998;11(4):589-603.

[2] Peleg AY, Hooper DC. Hospital-acquired infections due to gram-negative bacteria. N Engl J Med. 2010 May 13;362(19):1804-13.

[3] Zimlichman E, Henderson D, Tamir O, Franz C, Song P, Yamin C. K. et al. Health care-associated infections: a meta-analysis of costs and financial impact on the US health care system. JAMA Intern Med. 2013;173(22):2039-46. 
[4] Feng DY, Zhou YQ, Zou XL, Zhou M, Wu WB, Chen XX, et al. Factors influencing mortality in hospitalacquired pneumonia caused by Gram-negative bacteria in China. J Infect Public Health. 2019 Sep Oct;12(5):630-633.

[5] Versalovic J, Koeuth T, Lupski JR. Distribution of repetitive DNA sequences in eubacteria and application to fingerprinting of bacterial genomes. Nucleic Acids Res. 1991 Dec 25;19(24):6823-31.

[6] Dorneles EM, Santana JA, Ribeiro D, Dorella FA, Guimarães AS, Moawad MS, et al. Evaluation of ERICPCR as genotyping method for Corynebacterium pseudotuberculosis isolates. PLoS One. 2014 Jun 5;9(6):e98758.

[7] Miao M, Wen H, Xu P, Niu SQ, Lv JN, Xie XF, etc. Genetic Diversity of Carbapenem-Resistant Enterobacteriaceae (CRE) Clinical Isolates From a Tertiary Hospital in Eastern China. Front Microbiol. 2019 Jan 15;9:3341. [8] Zhang R, Liu L, Zhou H, Chan EW, Li YF, Li Y, et al. Nationwide Surveillance of Clinical Carbapenem-resistant Enterobacteriaceae (CRE) Strains in China. EBioMedicine. 2017 May;19:98106.

[9] Pal A, Dhara L, Tripathi A. Contribution of acrB upregulation \& OmpC/Ompk36 loss over the presence of bla $a_{\text {NDM }}$ towards carbapenem resistance development among pathogenic Escherichia coli \& Klebsiella spp. Indian J Med Res. 2019;149(4):528-38.

[10] Bush K, Jacoby GA. Updated functional classification of $\beta$-lactamases. Antimicrob Agents Chemother. 2010;54(3):969-976.

[11] Patel G, Bonomo RA. "Stormy waters ahead": global emergence of carbapenemases. Front Microbiol. 2013;4:48.

[12] Opal SM, Pop-Vicas A, Molecular Mechanisms of Antibiotic Resistance in Bacteria. In: Bennett JE, Dolin R, BlaserMandell MJ, editors. Douglas, and Bennett's Principles and Practice of Infectious Diseases (Eighth Edition), 2015;235-51.

[13] Tamma PD, Hsu AJ. Defining the Role of Novel $\beta$-Lactam Agents That Target Carbapenem-Resistant Gram-Negative Organisms. J Pediatric Infect Dis Soc. 2019;8(3):251-60.

[14] Schroeder JW, Yeesin P, Simmons LA, Wang JD. Sources of spontaneous mutagenesis in bacteria. Crit Rev Biochem Mol Biol. 2018 Feb;53(1):29-48. [15] Andersson DI. Persistence of antibiotic resistant bacteria. Curr Opin Microbiol. 2003 Oct;6(5):452-6. [16] Bush K, Bradford PA. $\beta$-Lactams and $\beta$-Lactamase Inhibitors: An Overview. ColdSpring Harb Perspect Med. 2016 Aug 1;6(8).

[17] Gutiérrez-Gutiérrez B, Bonomo RA, Carmeli Y, Paterson DL, Almirante B, Martínez-Martínez L, et al. : Ertapenem for the treatment of bloodstream infections due to ESBL-producing Enterobacteriaceae: a 
multinational pre-registered cohort study. J Antimicrob Chemother. 2016;71(6):1672-80.

[18] Zhao YB, Qu XY, Yin C, Lu XF, Zhang Z, Yin AT. Clinical application of carbapenem antibiotics in tertiary general hospitals: a cross-sectional study[J]. Chinese Journal of Public Health, 2018, 34(2): 285289.

[19] Hu FP, Guo Y, Zhu DM, Wang F, Jiang XF, Xu YC, et al. Resistance trends among clinical isolates in China reported from CHINET surveillance of bacterial resistance, 2005-2014 [J]. Clin Microbiol Infect. 2016;22(Suppl 1):S9-14.

[20] Chotiprasitsakul D, Srichatrapimuk S, Kirdlarp S, Pyden AD, Santanirand P. Epidemiology of carbapenem-resistant Enterobacteriaceae: a 5-year experience at a tertiary care hospital. Infect Drug Resist. 2019 Feb 20;12:461-8.

[21] Bell BG, Schellevis F, Stobberingh E, Goossens H, Pringle M. A systematic review and meta-analysis of the effects of antibiotic consumption on antibiotic resistance. BMC Infect Dis. 2014;14:13. Published 2014 Jan 9.

[22] Kohanski MA, DePristo MA, Collins JJ. Sublethal antibiotic treatment leads to multidrug resistance via radical-induced mutagenesis. Mol Cell. 2010;37(3):311-20.

[23] Hirayama S, Yasui K, Murakami H, Kosugi T, Sakamoto M, Hanai Y, et al. A new carbapenem drug dosage metric for carbapenem usage and correlation with carbapenem resistance of Pseudomonas aeruginosa. J Infect Chemother. 2018;24(12):949-53.

[24] Köck R, Daniels-Haardt I, Becker K, Mellmann A, Friedrich AW, Mevius D, et al. Carbapenem-resistant Enterobacteriaceae in wildlife, food-producing, and companion animals: a systematic review. Clin Microbiol Infect. 2018;24(12):1241-1250.

[25] Munita JM, Arias CA. Mechanisms of Antibiotic Resistance. Microbiol Spectr. 2016;4(2):10.1128/microbiolspec.VMBF-0016-2015.

[26] van Loon K, Voor In 't Holt AF, Vos MC. A Systematic Review and Meta-analyses

of the Clinical Epidemiology of Carbapenem-Resistant Enterobacteriaceae. Antimicrob Agents Chemother. 2017 Dec 21; 62(1).

[27] Qiao M, Ying GG, Singer AC, Zhu YG. Review of antibiotic resistance in China and its environment. Environ Int. 2018;110:160-172.

\section{Figures}




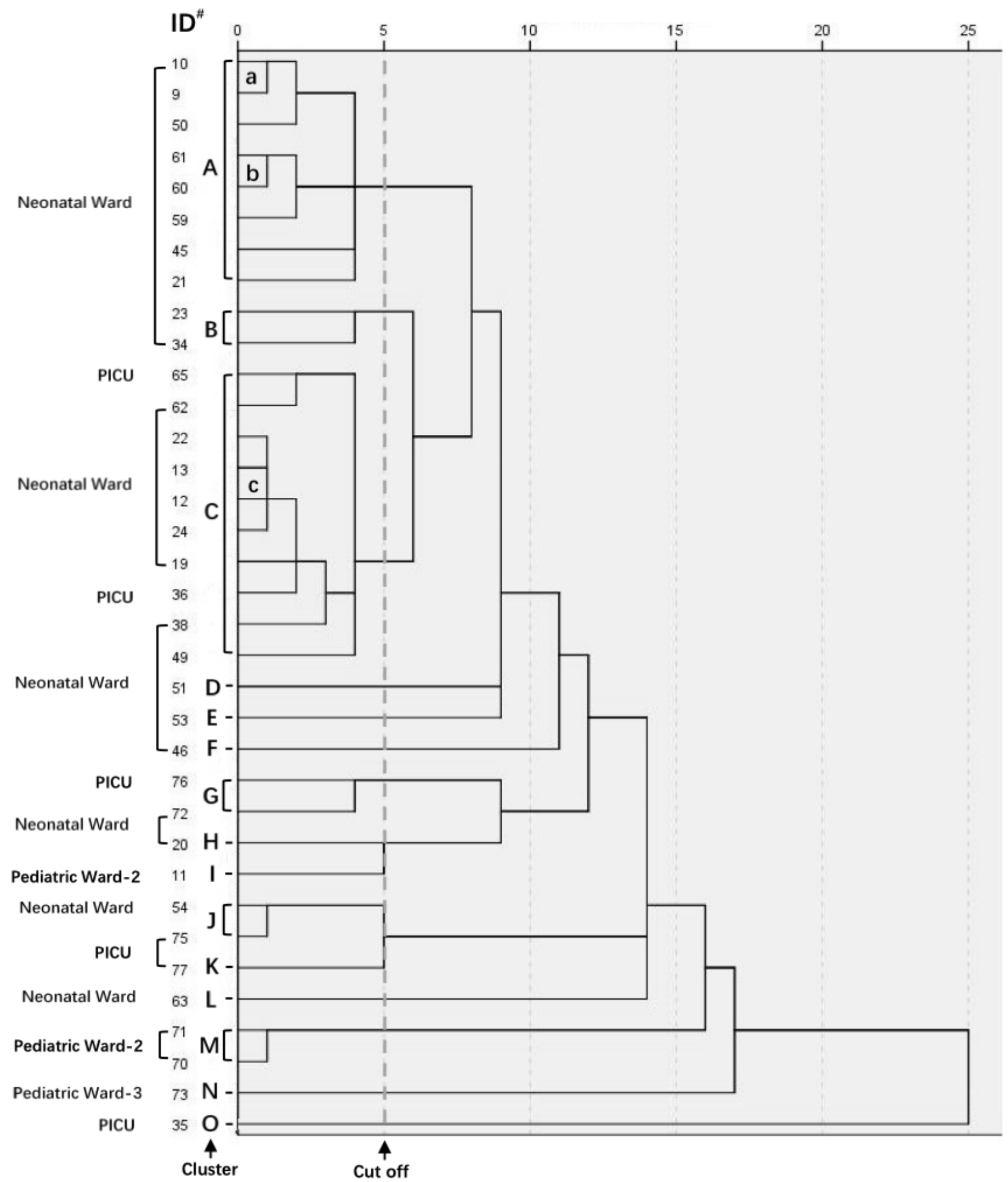

\section{Figure 1}

Dendrogram of 35 imipenem-resistant Klebaiella pneumoniae Dendrogram using Average (BetweenGroup) Linkage shows the genetic relationship among the isolates based on the ERIC-PCR results. The number 0 to 25 at the top horizontal scale is the relative distance between the strains. The numbers of vertical axis at the left of figure are sample numbers and the capital letters A-O indicate the clusters of 
isolates which have a high genetic similarity ( $<5$ relative distance). The lower case letters a-c indicate the sub-clusters of the isolates within a cluster, which have the lowest relative distance.

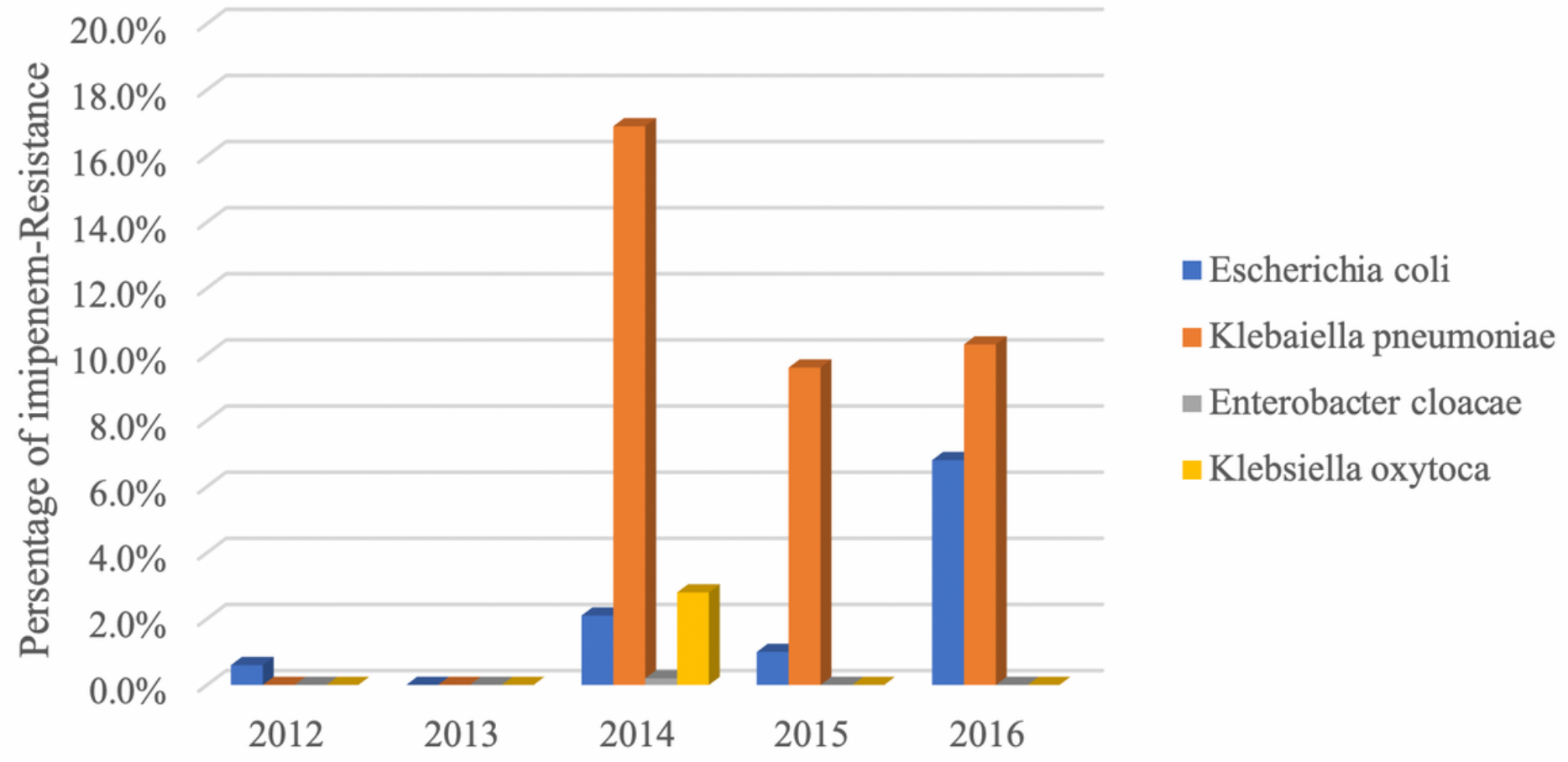

Figure 2

2 The percentage of imipenem-resistant Enterobacteriaceae pathogens Rates (\%) of imipenem resistant isolates of 4 commonly known bacterial pathogens (Escherichia coli, Klebaiella pneumoniae, Enterobacter cloacae and Klebsiella oxytoca) are shown.

\section{Supplementary Files}

This is a list of supplementary files associated with this preprint. Click to download.

- Additionalfile1.docx

- Additionalfile1.docx 